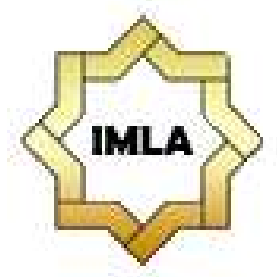

\author{
Al-Ta'rib \\ Jurnal Ilmiah Program Studi Pendidikan Bahasa Arab \\ IAIN Palangka Raya \\ Vol. 8, No. 2, December 2020, 201-212 \\ p-ISSN 2354-5887 | e-ISSN 2655-5867 \\ DOI: https://doi.org/10.23971/altarib.v8i2.2258
}

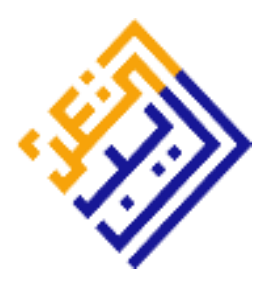

\title{
METODE QUANTUM TEACHING SEBAGAI SOLUSI ALTERNATIF PEMBELAJARAN BAHASA ARAB DI ERA NEW NORMAL
}

\author{
Maftuhatul Umamah' ${ }^{1}$, Abdul Muntaqim Al Anshory ${ }^{2}$, Sutaman ${ }^{3}$ \\ 1,2,3Universitas Islam Negeri Maulana Malik Ibrahim Malang, Indonesia \\ E-mail: maftuhatulumamah@gmail.com
}

\begin{abstract}
This study aims to explain the basic concepts, the implementation and the benefits of the Quantum Teaching method in learning Arabic which is effective in the new normal era. This research is a qualitative descriptive research. Data collection techniques used were observation, interviews and documentation, with qualitative data analysis techniques; Miles and Huberman: data reduction, data display, and conclusion drawing. The results showed that the application of the Quantum Teaching method can increase the students' learning motivation and students' learning outcomes according to the minimum completeness criteria. Therefore, this method can be used as an alternative for active learning in the new normal period. The application of this method also has drawbacks, such as the existence of several activities that can interfere with other class learning activities such as singing and clapping hands in order to give the symbols of appreciation or praise to students for the achievement of their learning outcomes. Researcher hopes that this study research can become a reference for the Arabic teachers in choosing Arabic learning methods actively which are able to foster students' creativity to produce innovation in the learning process.
\end{abstract}

Keywords: Quantum Teaching; Arabic Learning; New normal

\begin{abstract}
Abstrak
Penelitian ini bertujuan untuk menjelaskan konsep dasar, implementasi dan manfaat metode Quantum Teaching dalam pembelajaran bahasa Arab yang efektif pada masa new normal. Penelitian ini merupakan jenis penelitian deskritif kualitatif. Teknik pengumpulan data yang digunakan adalah observasi, wawancara dan dokumentasi, dengan teknik analisa data kualitatif Miles dan Huberman: reduksi data, display data, dan Conclusion drawing. Hasil penelitian menunjukkan bahwa penerapan metode Quantum Teaching dapat meningkatkan motivasi belajar siswa dan hasil belajar siswa sesuai kriteria ketuntasan minimal. Maka dari itu, metode ini dapat menjadi salah satu alternatif pembelajaran aktif di masa new normal. Penerapan metode ini juga memiliki kekurangan seperti adanya beberapa aktifitas yang daoat mengganggu aktifitas belajar kelas lain seperti bernyanyi dan bertepuk tangan guna memberikan simbol penghargaan atau pujian kepada siswa atas prestasi hasil belajar yang telah mereka raih. Peneliti berharap bahwa penelitian ini
\end{abstract}


dapat menjadi rujukan para pengajar bahasa arab dalam memilih metode pembelajaran bahasa Arab secara aktif yang mampu menumbuhkan kreatifitas siswa untuk berinovasi dalam proses pembelajaran.

Kata Kunci: Quantum Teaching; Pembelajaran Bahasa Arab; New normal

\section{Pendahuluan}

Memasuki tahun ajaran baru, tepatnya pada tanggal 13 Juli 2020, segala persiapan telah direncanakan memasuki era baru atau new normal. Fase normal merupakan aturan pola hidup baru di tengah wabah Covid-19. Selama diberlakukan masa era baru atau new normal, aturan kebijakan dan aturan protokol kesehatan Covid-19 tetap diterapkan, termasuk di sektor Pendidikan (A.Irawan Rasanjani, n.d.). Sistem kurikulum pembelajaran misalnya, setiap lembaga pendidikan wajib menyesuaikannya dengan peraturan selama diberlakukannya masa new normal. Hal ini dilakukan supaya proses pembelajaran bisa terus berjalan ("Panduan Pembelajaran Jarak Jauh dari Kemendikbud Selama Masa New normal," 2020)

Semenjak diberlakukannya masa new normal di Indonesia, sudah ada beberapa wilayah pendidikan yang menerapkan sistem tersebut. Hal ini juga berpengaruh pada pembelajaran bahasa Arab. Pembelajaran Bahasa Arab yang selama ini dianggap hanya sebagai alat belajar untuk berkomunikasi ternyata bisa membawa merdeka belajar buat siswa terutama untuk mengembangkan pengalaman, kolaborasi dan prestasi siswa (Fahrurrozi, 2014).

Dalam pembelajaran bahasa Arab di era new normal ini, sangat dibutuhkan suatu model atau metode yang sangat efektif yang dapat mewujudkan tujuan pembelajaran yang selaras dengan kurikulum 2013 (Asy'ari, 2019). Pembelajaran bahasa Arab di SMA Darul Quran pada masa new normal ini masih kurang maksimal. Hal tersebut terlihat pada beberapa faktor baik dari guru maupun siswa, penguasaan yang muncul pada guru karena kurangnya penguasaan model, strategi dan metode pembelajaran dan pendekatan yang digunakan di dalam kelas. Sedangkan permasalahan yang muncul dari siswa, rendahnya motivasi belajar di kelas, kurang percaya diri dalam komunikasi berbicara bahasa Arab, serta rendahnya nilai KKM (Kriteria Ketuntasan Minimal) pelajaran bahasa Arab baik pada aspek kognitif dan praktek dari empat maharah dalam pembelajaran bahasa Arab (Yanto, 2018).

Sesuai dengan problematika diatas, untuk itu perlu solusi alternatif pendekatan pembelajaran yang komprehensif. Guru harus dapat memilih metode pembelajaran yang sesuai dengan tingkat perkembangan siswa. Guru juga harus memiliki keterampilan dalam merancang, mengembangkan dan mengelola sistem pembelajaran sehingga guru mampu menciptakan pembelajaran yang efektif, menggairahkan dan kegiatan pembelajaran yang menarik, menantang dan dapat mengembangkan kecakapan berfikir siswa (Widiyaningsih \& Pujiastuti, 2013), serta melibatkan siswa secara aktif dalam kegiatan pembelajaran. Salah satu model pembelajaran yang dapat digunakan untuk mengatasi masalah pembelajaran tersebut adalah model pembelajaran Quantum Teaching. "Quantum Teaching merupakan interaksi yang mengubah energi menjadi cahaya" (Kosasih dan Sumarna, 2013:75). Pengembangan aspek-aspek tersebut sangat erat kaitannya 
dengan konsep pada metode Quantum Teaching yang syarat dalam memudahkan siswa untuk mengeksplorasi semua aspek, fikiran, gagasan, minat, bakat keyakinan dan pandangan akan masa depan yang ada dalam diri mereka (Monk-Turner Elizabeth, 2020). Bobby De Porter mengatakan bahwa Quantum Teaching adalah konsep yang menguraikan cara-cara baru dalam memudahkan proses belajar mengajar, lewat pemaduan unsur seni dan pencapaian-pencapaian yang terarah, apapun mata pelajaran yang diajarkan (Yanuarti \& Sobandi, 2016).

Sebagaimana yang dijelaskan oleh Yatim Riyanto (2010:199), Quantum Teaching (QT) adalah pengubahan belajar yang meriah, dengan segala nuansanya, serta menyertakan segala kaitan, interaksi dan perbedaan yang memaksimalkan momen belajar. Quantum Teaching berfokus pada hubungan yang dinamis dalam lingkungan kelas, interaksi yang mendirikan berupa kerangka belajar (Arianti, 2018). Model Quantum Teaching sanga efektif dan efisien diterapkan untuk mengembangkan potensi minat bakat dan hasil belajar siswa (Goman Rumapea, n.d.). Menurut pendapat Colin Rose bahwa Quantum Teaching adalah panduan praktis dalam mengajar yang berusaha mengakomodir setiap bakat siswa atau dapat menjangkau setiap siswa. Metode ini sangat cocok dengan penemuanpenemuan terkini yang menimbulkan antusiasme siswa. Dengan kata lain, bentuk interaksi dalam Quantum Teaching dan proses pembelajarannya yang tercipta akan berpengaruh besar sekali terhadap efektivitas dan antusiasme belajar siswa. Hal terpenting dalam pembelajaran bahasa Arab adalah menumbuhkan dalam jiwa siswa semangat dan keinginan yang kuat untuk mempelajari bahasa Arab (Setyawan \& Fathoni, 2018).

Studi penggunaan metode ini cenderung membuat guru harus benar-benar terampil dalam membuat konsep pembelajarannya agar proses pembelajaran lebih efektif, siswa yang pasif menjadi aktif dan bersemangat untuk belajar, begitu juga sarana dan prasarana kelas yang harus memadai karena semua peralatan kelas sangat bermakna dalam pembelajaran karena segalanya berbicara dan segalanya bertujuan (Suryani, n.d.). Berbagai persoalan dalam pembelajaran bahasa Arab di masa pandemi dan era new normal ini menghambat pembelajaran bahasa Arab dapat diatasi dengan kreatifitas guru dalam mengoraganisasikan kelas melalui metode yang tepat sehingga tujuan pembelajaran tetap bisa tercapai. Melalui metode Quantum Teaching and learning dapat merubah paradigma siswa bahwa belajar bahasa Arab itu lebih mudah dan menyenangkan, mengalirkan energi positif pada siswa untuk bisa meraih prestasi dan kemandirian dalam kehidupan mereka. Cara paling signifikan dalam metode Quantum Teaching ini adalah pemaduan unsur seni. Salah satu keistimewaan dari metode Quantum Teaching adalah tercapainya prestasi siswa (Suryani, n.d.).

Ada beberapa penelitian terdahulu tentang pendekatan Quantum Teaching dalam pembelajaran Bahasa Arab, yakni: Penelitian dengan judul “ Desain Konsep Pembelajaran Bahasa Arab dengan Model Quantum Teaching di STAI Masjid Syuhada Yogyakarta". secara umum, penelitian ini bertujuan mengimplementasikan model Quantum Teaching untuk meningkatkan motivasi belajar siswa agar lebih menarik dan menyenangkan (Setyawan \& Fathoni, 2018).

Penelitian yang berjudul "Peningkatan Keterampilan Menulis Bahasa Arab dengan Model Quantum Teaching Teknik Tandur Pada Siswa Kelas VIII SMP Islam Moga Kabupaten Pemalang Tahun 2011. Penelitian ini bertujuan untuk 
mendeskripsikan perubahan perilaku siswa setelah diterapkan model pembelajaran Quantum Teaching dengan teknik TANDUR dalam pembelajaran menulis bahasa Arab, dan implikasi model pembelajaran tersebut untuk meningkatkan kemampuan ketrampilan menulis Bahasa Arab yang diterapkan oleh guru pengampu mata pelajaran bahasa Arab (Vera Strisly, 2011). Bahkan dari hasil penelitian lainnya menunjukkan bahwa metode Quantum Teaching mampu mengubah persepsi siswa bahwa bahasa Arab itu sulit menjadi menyenangkan diharapkan akan menghilangkan sterotip siswa tersebut dengan sendirinya (Awaliah Musgamy, n.d.).

fakta ini juga di dukung oleh penelitian Husnah $\mathrm{Z}$ menunjukkan bahwa hasil belajar Bahasa Arab peserta didik yang menggunakan metode Quantum Teaching memperoleh peningkatan signifikan karena hampir semua peserta didik memiliki nilai di atas rata-rata (Husnah, 2017). hal ini juga dibuktikan dengan hasil penelitian Susanti (2019) yang melaporkan bahwa implementasi strategi pembelajaran yang berbasis Quantum Teaching dapat meningkatkan keterampilan membaca bahasa Arab siswa (Susanti, 2019).

Penelitian ini dimaksudkan untuk melihat proses pembelajaran bahasa Arab dengan menggunakan metode Quantum Teaching sebagai alternatif solusi yang bisa digunakan pada era new normal. Berdasarkan hal tersebut, penelitian ini bertujuan untuk mengetahui; pertama, Bagaimana konsep implementasi Quantum Teaching dalam pembelajaran bahasa Arab pada era new normal. Kedua, Bagaimana implementasi metode Quantum Teaching dalam pembelajaran bahasa Arab pada era new normal. Ketiga Bagaimana manfaat implementasi metode Quantum Teaching dalam pembelajaran bahasa Arab.

Penelitian ini memiliki tiga asumsi mendasar yaitu: pertama, pembelajaran bahasa Arab di era new normal ini membutuhkan metode yang cocok dan tepat sesuai dengan kondisi siswa yang merupakan solusi alternatif dan strategi belajar yang menarik membiasakan dan hemat biaya; kedua, metode ini dapat diterapkan dalam empat maharah/keterampilan berbahasa (istima', kalam, qiroah dan kitabah ); ketiga, dengan pendekatan ini, siswa lebih antusias dan lebih bersemangat dalam pembelajaran bahasa Arab yang berprinsip pada learning to do, learning to be, leraning to know learning together. Dari ketiga asumsi tersebut, pendekatan metode Quantum Teaching dan learning diharapkan mampu merealisasikan tujuan dari pada pembelajaran bahasa Arab secara maksimal di era new normal dan merdeka belajar (Inovasi Penelitian_PBA_Muhbib.Pdf, n.d.)

\section{Metode}

Penelitian ini menggunakan pendekatan deskriptif kualitatif dengan cara menggambarkan dan mengekplorasikan proses penggunaan metode Quantum Teaching dalam pembelajaran bahasa Arab di era new normal dan merdeka belajar. Penelitian ini berlokasi di SMA Darul Quran kota Mojokerto.

Adapun partisipan dalam penelitian ini adalah guru bahasa Arab dan siswa kelas XI IPA berjumlah 35 orang, yang terdiri dari para siswa yang mengikuti program takhassus bahasa dan tahfidzul quran. Sedangkan kriteria guru bahasa Arabn dipilih berdasarkan kompetensi pedagogik mengajar yang professional sehingga mampu mengelola pembelajaran kelas dengan baik sehingga tujuan pembelajaran dapat tercapai. 
Data dan informasi dalam penelitian ini dikumpulkan melalui beberapa tehnik yaitu observasi, wawancara terbuka dan dokumentasi. Observasi dilakukan secara kontinyu, sistematis, dan terstruktur pada saat pembelajaran berlangsung, mengamati gejala-gejala atau kendala-kendala yang diteliti. Kegiatan observasi ini meliputi pemilihan, pengubahan, pencatatan, daftar cek list, dan pengkodean. Wawancara dilakukan terhadap dua orang guru bahasa Arab di kelas XI SMA Darul Quran Kota Mojokerto untuk menggali data tentang pelaksanaan penerapan metode Quantum Teaching (perencanaan, pelaksanaan dan evaluasi). Wawancara dengan siswa untuk memperoleh informasi tentang pendapat mereka terkait penerapan penerapan metode Quantum Teaching dan learning (Sugiyono, 2014, p. 250).

Penelitian ini menggunakan teknik analisa data kualitatif model Miles dan Huberman (1984) yaitu: 1) Reduksi data adalah merangkum data dari observasi, wawancara dan dokumentasi memilih hal- hal yang pokok sesuai yang di teliti. (2) Display data, yaitu dilakukan dalam bentuk uraian singkat atau grafik implementasi metode Quantum Teaching, 3) Conclusion drawing/verification, yaitu penarikan kesimpulan dan verifikasi dari reduksi data dan display data (Sugiyono, 2014, p. 252).

\section{Hasil Penelitian dan Pembahasan}

Berdasarkan pada paparan dari data hasil observasi, wawancara dan dokumentasi yang ada dilapangan, peneliti akan membahas terkait dengan implementasi metode Quantum Teaching pada pembelajaran bahasa Arab sebagai berikut:

\section{Konsep Metode Quantum Teaching dan Learning Dalam Pembelajaran Bahasa Arab}

Konsep metode Quantum Teaching dalam pembelajaran bahasa Arab sangat dipengaruhi oleh peran guru sebagai aktor di dalam kehidupan siswa ketika berada di kelas, yang bisa memahami karakter, kompetensi tiap siswa yang berbeda dalam memahami setiap keterampilan istima', kalam, qira'ah dan kitabah.

Konsep dasar Quantum Teaching dalam pembelajaran bahasa Arab di SMA Darul Quran Mojokerto bertujuan untuk membawa siswa sukses belajar bahasa Arab yang mengacu pada pedoman kerangka Quantum Teaching yaitu: tumbuhkan, alami, namai, demonstrasikan, ulangi, dan rayakan, yang disingkat dengan istilah TANDUR (Suryani, n.d.)

Adapun penjelasan konsep dasar Quantum Teaching dalam pembelajaran bahasa Arab di SMA Darul Quran Mojokerto sebagaimana terlihat pada bagan 1 adalah sebagaimana berikut. 
Bagan. 1

Konsep Metode Quantum Teaching dan Learning dalam Pembelajaran

Bahasa Arab di Era New normal di SMA Darul Quran Mojokerto.

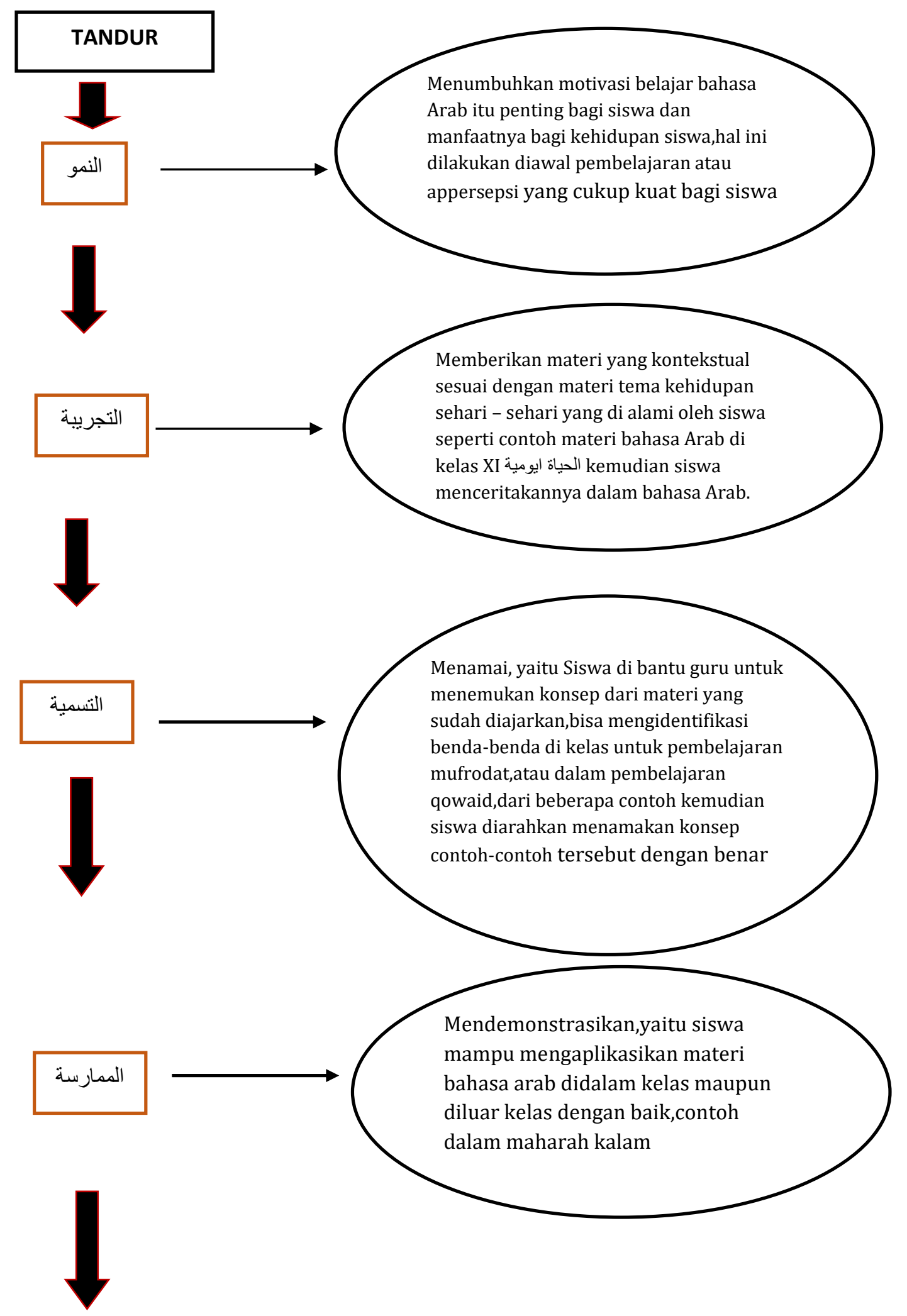

Jurnal Ilmiah Program Studi Pendidikan Bahasa Arab IAIN Palangka Raya Vol. 8, No. 2 |201-212 Al-Ta'rib | p-ISSN 2354-5887 | e-ISSN 2655-5867 


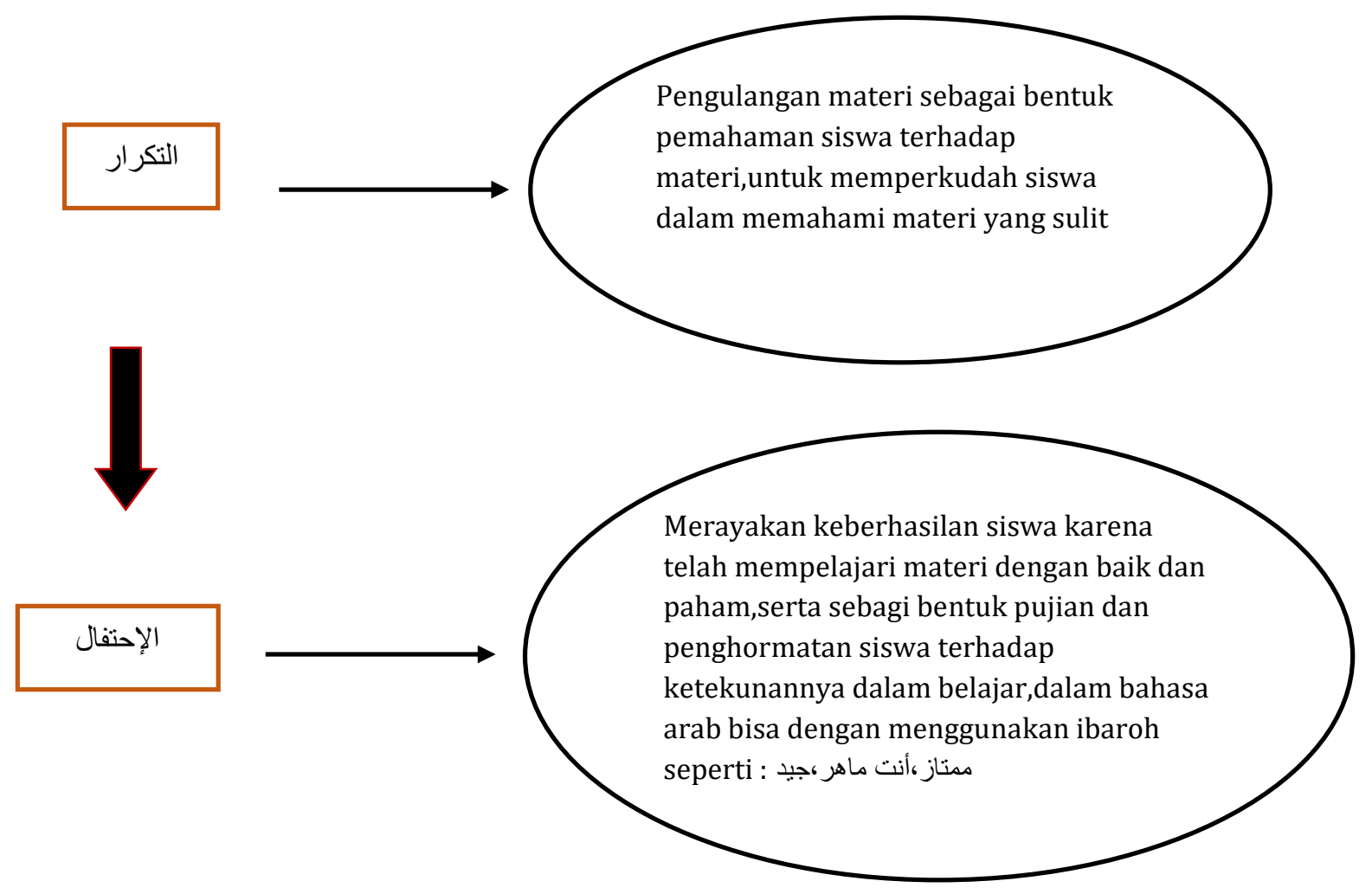

Dari bagan 1 di atas, konsep Quantum Teaching menjadi tepat diterapkan dalam pembelajaran bahasa Arab di era new normal dengan memperhatikan pemetaan materi-materi yang esensial yang menjadikan tujuan pembelajaran bermakna bagi siswa.

Dari beberapa hasil penelitan dengan menggunakan metode QT ini, baik dalam bidang bahasa arab maupun bidang sains, hal ini selaras dengan tujuan dan hasil penelitian yang di kaji peneliti bahwa metode QT ini sangat efektif dan relevan diimplementasikan dalam pembelajaran baik secara offline dan online. Hal tersebut dapat dilihat dari meningkatnya motivasi siswa, prestasi siswa dan hasil belajar siswa.

Dari Hasil kajian penelitian ini ditemukan bahwa penerapan metode QT yang diterapkan di lembaga Darul Quran Kota Mojokerto, bisa digunakan dalam empat maharah dengan cara belajar, visual, auditory, dan kinesthetic.

\section{Implementasi Metode Quantum Teaching dan Leraning dalam Pembelajaran Bahasa Arab}

Pada proses awal, peneliti melakukan observasi dan hadir di kelas untuk melihat proses pembelajaran secara luring atau tatap muka. Peneliti menemukan beberapa kendala saat pembelajaran bahasa Arab berlangsung seperti pengurangan jam belajar atau tatap muka, perampingan materi atau kompetensi dasar, kejenuhan siswa, kurangnya kreativitas siswa, dan minimnya media pembelajaran.

Pelaksanaan Pembelajaran bahasa Arab dengan metode Quantum Teaching di SMA Darul Quran Mojokerto mengikuti model TANDUR (Yanuarti \& Sobandi, 2016) dan pada umumnya memenuhi setiap keterampilan bahasa sebagaimana berikut; pertama, bahan ajar didengarkan dan dibacakan dengan modifikasi berupa musik yang berfungsi sebagai penguatan/reinforcement (maharah istima'). Kedua, menggunakan media gambar atau film sebagai penguatan/reinforcement 
bacaan atau teks yang ditransfer secara lisan atau tulisan (maharah qiroa'h), Ketiga, kinestetik guru bisa memacu pemahaman para siswa dengan mengajak mereka untuk bermain peran (role play) terlebih dahulu sebagai brain storming yang akan memacu pemahaman mereka terhadap pembelajaran yang sedang dilakukan (maharah kalam dan kitabah).

Secara umum, implementasi metode Quantum Teaching dalam pembelajaran bahasa Arab di era new normal di SMA Darul Quran Mojokerto dilakukan dalam beberapa tahapan, yakni: pertama, Guru menyiapkan panduan materi pembelaran bahasa Arab yang meliputi Silabus, RPP, dan evaluasi. kedua, Guru menentukan topik materi dalam pembahasan, kompetensi dasar, dan tujuan pembelajaran. ketiga, Guru memberikan apersepsi motivasi kepada siswa tentang pentingnya mempelajari bahasa arab, materi dan kaidahnya bahasa bagi kehidupan siswa. Keempat, guru mulai memaparkan gambar-gambar atau bendabenda melaui slide power point atau tayangan video terkait kata-kata pada teks bacaan الحياة اليومية, kemudian siswa mulai menyebutkan kosakata dalam slide power point tersebut. Kelima, siswa menyimak dan memahami tampilan yang ditayangkan dan mendiskusikannya. Keenam, masing-masing siswa atau kelompok mempresentasikan hasil diskusinya di depan kelas dengan diiringi instrument music volume rendah agar siswa merasa nyaman dan kondusif. Ketujuh, Guru memberikan apresiasi atau pujian berupa tepuk tangan atau dengan kata-kata "jayyid" atau "Mumtaz" atas hasil yang telah mereka selesaikan dengan baik. Kedelapan, Guru memberikan evaluasi berupa tes akhir pada setiap KD yang diajarkan dengan tujuan untuk mengetahui hasil belajar yang telah dilaksanakan.

Tahapan-tahapan implementasi pembelajaran bahasa Arab di era new normal di SMA Darul Quran Mojokerto bisa dilihat pada bagan 2 berikut.

\section{Bagan. 2. \\ Tahapan-tahapan Implementasi Pembelajaran Bahasa Arab dengan Metode Quantum Teaching}

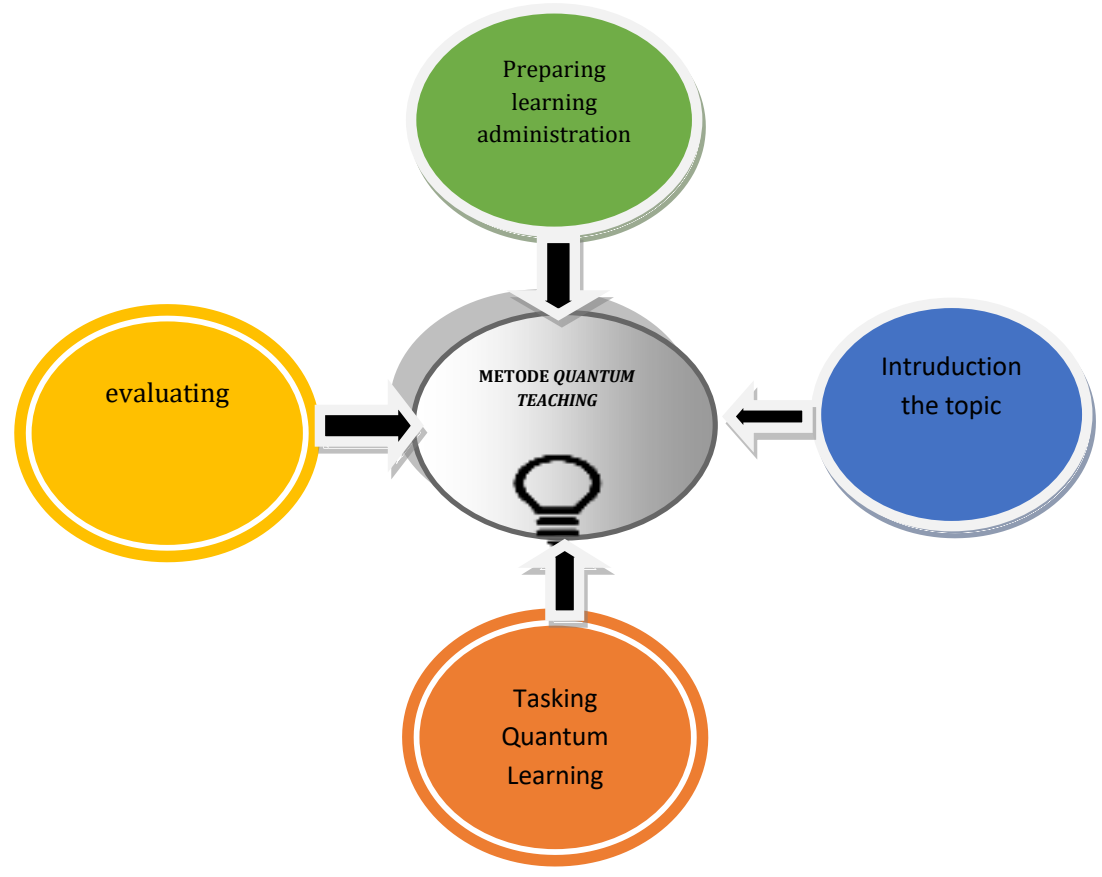

Jurnal Ilmiah Program Studi Pendidikan Bahasa Arab IAIN Palangka Raya Vol. 8, No. 2 |201-212 Al-Ta'rib | p-ISSN 2354-5887 | e-ISSN 2655-5867 


\section{Manfaat Metode Quantum Teaching dan Leraning dalam Pembelajaran Bahasa Arab di Era New normal di SMA Darul Quran Mojokerto}

Beberapa manfaat implementasi metode Quantum Teaching dalam pembelajaran bahasa Arab di SMA Darul Quran Mojokerto, yakni: a) terciptanya suasana kelas menyenangkan sehingga peserta didik bergairah dan semangat belajar. siswa lebih aktif untuk mengikuti proses pembelajaran, karena materi yang disampaikan adalah materi yang kontekstual sesuai dengan realitas kehidupan siswa, b) siswa mampu memahami betapa pentingnya materi yang di ajarkan, dan bisa merasakan manfaat dari tujuan materi yang disampaikan, karena sesuai dengan praktek kondisi yang real dialami siswa, c) penghargaan terhadap apapun yang dilakukan oleh siswa sebagai bentuk motivasi terhadap hasil yang sudah dicapai dalam belajar berupa pujian, hadiah, tepuk tangan, atau ucapan terima kasih. Hal ini dilakukan sebagai umpan balik emosi positif dalam belajar. Siswa menjadi semangat belajar dan prestasi nilai hasil belajar menjadi meningkat. Guru juga terlatih untuk berfikir dan kreatif, inovatif dalam pembelajaran, sehingga tujuan dari pembelajaran bahasa Arab bisa tercapai dengan maksimal.

Adapun kekurangan dari metode ini adalah: (1) perlu perencanaan yang matang dan waktu yang cukup, (2) perlu peralatan dan tempat yang memadai dan biaya yang cukup besar, (3) perayaan yang dilakukan dapat mengganggu kelas lain, (4) menuntut keterampilan guru secara khusus, (5) menuntut ketelitian dan kesabaran.

\section{Kesimpulan}

Pembelajaran bahasa Arab pada masa new normal perlu adanya inovasi, yaitu dengan cara menciptakan suasana pembelajaran yang nyaman dengan cara memanfaatkan unsur yang ada pada siswa dan lingkungan belajarnya melalui interaksi pembelajaran yang terjadi di dalam kelas sehingga antusiasme peserta didik untuk memahami materi yang diberikan, sehingga tujuan pembelajaran dapat tercapai secara maksimal.

Penelitian ini memiliki keterbatasan, menuntut dan memerlukan ketrampilan guru lebih khusus, memerlukan proses perancangan dan persiapan pembelajaran yang cukup matang dan terencana dengan cara yang lebih baik. Peneliti menyarankan agar pembelajaran bahasa Arab dengan metode Quantum Teaching ini membutuhkan konsep yang matang dan guru yang professional serta memiliki kompetensi dan keterampilan dalam mengolah pembelajaran aktif,kreatif,inovatif dan menyenangkan.

\section{Referensi}

A.Irawan Rasanjani, A. I. R. (n.d.). Kebijakan di Era New normal.

Arianti, R. (2018). Implementation Of Quantum Teaching Models in Listening The Short Stories in SMA 2 Rambah Hilir (Penerapan Model Quantum Teaching Dalam Menyimak Cerita Pendek Di Sma Negeri 2 Rambah Hilir). Gramatika 
STKIP PGRI Sumatera Barat, https://doi.org/10.22202/jg.2018.v4i2.2555

Asrori Imam, T. M. (2017). Evaluasi Pembelajaran Bahasa Arab. Misykat.

Asy'ari, M. (2019). Metode, Sistem dan Prinsip Pembelajaran Bahasa Arab yang Inovatif. An Nabighoh: Jurnal Pendidikan Dan Pembelajaran Bahasa Arab, 20(02), 288-306. https://doi.org/10.32332/an-nabighoh.v20i02.1465

Awaliah Musgamy. (n.d.). Quantum Learning sebagai Proses Pembelajaran Bahasa Arab Aktif, Inovatif, Kreatif, Efektif dan Menyenangkan.

Fahrurrozi, A. (n.d.). Problematika Bahasa Arab dan Solusinya.

Fahrurrozi, A. (2014). Pembelajaran Bahasa Arab: Problematika dan Solusinya. ARABIYAT: Jurnal Pendidikan Bahasa Arab dan Kebahasaaraban, 1(2), 161180. https://doi.org/10.15408/a.v1i2.1137

Goman Rumapea, E. S. (n.d.). Application of Quantum Teaching Learning Model to Improve Student Learning Outcomes.

Husnah, H. (2017). Efektivitas Penerapan Metode Quantum Teaching Terhadap Peningkatan Hasil Belajar Bahasa Arab Siswa MAN Polewali Mandar. JPPI (Jurnal Pendidikan Islam Pendekatan Interdisipliner), 1(1), 80-91. https://doi.org/10.36915/jpi.v1i1.38

Inovasi Penelitian_PBA_Muhbib.pdf. (n.d.).

Monk-Turner Elizabeth. (2020). Epistemology, social inquiry and quantum theory. Qualitative Research Journal, 20(2), 228-242. https://doi.org/10.1108/QRJ10-2019-0085

Panduan Pembelajaran Jarak Jauh dari Kemendikbud Selama Masa New normal. (2020, August 7). Kelas Pintar. https://www.kelaspintar.id/blog/edutech/panduan-pembelajaran-jarakjauh-dari-kemendikbud-6343/

Setyawan, C. E., \& Fathoni, M. (2018). Desain Konsep Pembelajaran Bahasa Arab dengan Model Quantum Teaching. Al-Ta'rib: Jurnal Ilmiah Program Studi Pendidikan Bahasa Arab IAIN Palangka Raya, 6(1), 60-79. https://doi.org/10.23971/altarib.v6i1.1010

Sugiyono, S. (2014). Metode penelitian kuantitatif kualitatif dan R\&D. Alfabeta.

Suryani, K. (n.d.). Efektifitas Pendekatan Quantum Teaching dalam Memotifasi Minat Belajar Bahasa Arab. 22.

Susanti, Y. (2019). Meningkatkan Keterampilan Membaca Bahasa Arab Melalui Model Quantum Teaching di MAN 3 Padang Panjang. Lughawiyah: Journal of Arabic Education and Linguistics, 1(1), Article 1. https://doi.org/10.31958/lughawiyah.v1i1.1525

Vera Strisly, V. S. B. A. (2011). Peningkatan ketrampilan Menulis Bhasa Arab Dengan Model Pembekajaran Quantum Teaching Teknik Tandur Pada siswa Kelas VIII SMP Islam moga Kabupaten Pemalang Tahun 2011. 
Widiyaningsih, E., \& Pujiastuti, E. (2013). Keefektifan Pembelajaran Model Quantum Teaching Berbantuan Cabri 3D Terhadap Kemampuan Pemecahan Masalah. Kreano, Jurnal Matematika Kreatif-Inovatif, 4(1), 98-104. https://doi.org/10.15294/kreano.v4i1.2886

Yanto, A. (2018). Upaya Meningkatkan Pemahaman Konsep Melalui Model Pembelajaran Quantum Teaching. Indonesian Journal of Learning Education and Counseling, 1(1), 11-16. https://doi.org/10.31960/ijolec.v1i1.9

Yanuarti, A., \& Sobandi, A. (2016). Upaya Meningkatkan Hasil Belajar Siswa Melalui Penerapan Model Pembelajaran Quantum Teaching. Jurnal Pendidikan Manajemen Perkantoran, 1(1), 11. https://doi.org/10.17509/jpm.v1i1.3261

\section{Copyright Notice}

Authors retain copyright and grant the journal right of first publication with the work simultaneously licensed under a Creative Commons Attribution 4.0 International License that allows others to share the work with an acknowledgement of the work's authorship and initial publication in this journal. 
HALAMAN INI SENGAJA DIKOSONGKAN 